\title{
Creation of a contusion injury method for skeletal mus- cle in rats with differing impacts ${ }^{1}$
}

Milla Gabriela Belarmino Dantas', Camila Mahara Dias Damasceno", Vanessa Raquel Pinto de Barro$s^{\prime \prime \prime}$, Eveline Soares Menezes ${ }^{\mathrm{IV}}$, Humberto de Sousa Fontourav, Ricardo Santana de Limav, Ferdinando Oliveira Carvalho VII, Jackson Roberto Guedes da Silva Almeida VIII

'Fellow Master degree, Postgraduate Program in Health and Biological Sciences, Center for Studies and Research of Medicinal Plants, Universidade Federal do Vale do São Francisco (UNIVASF), Petrolina-PE, Brazil. Technical procedures, acquisition and interpretation of data, macroscopic and histopathological examinations, manuscript preparation.

"Master, Center for Studies and Research of Medicinal Plants, UNIVASF, Petrolina-PE, Brazil. Technical procedures, acquisition and interpretation of data.

I'Fellow PhD degree, Rede Nordeste de Biotecnologia, UNIVASF, Petrolina-PE, Brazil. Technical procedures, acquisition of data, macroscopic and histopathological examinations.

IV Fellow Master degree, Postgraduate Program in Functional and Molecular Biology, Universidade de Campinas (UNICAMP), Campinas-SP, Brazil. Technical procedures, manuscript preparation.

${ }^{\vee} P h D$, Associate Professor, Universidade Estadual de Goiás (UEG), Brazil. Scientific and intellectual content of the study. V'PhD, Associate Professor, Department of Medicine, UNIVASF, Petrolina-PE, Brazil. Technical procedures, acquisition of data, macroscopic and histopathological examinations.

VIIPhD, Associate Professor, Department of Physical Education, UNIVASF, Petrolina-PE, Brazil. Interpretation of data, critical revision.

VIIIPhD, Associate Professor, Center for Studies and Research of Medicinal Plants, UNIVASF, Petrolina-PE, Brazil. Scientific and intellectual content of the study, interpretation of data, critical revision. CNPq Research Productivity Scholarship Level 2.

\section{Abstract}

Purpose: To realize a morphological examination of the musculoskeletal tissue, assessing the effect of a contusion method for the production in rat gastrocnemius, comparing the inflammatory responses generated by different impacts.

Methods: For the analysis of a contusion method, twelve female Wistar rats were distributed into four groups. The lesion was generated by $324 \mathrm{~g}$ of mass that was dropped from different predetermined heights for each group $(30,45,60$ and $70 \mathrm{~cm})$.

Results: In the analysis of musculoskeletal tissue, the response to injury varied according to the mass of the height drop onto the muscle. Only the group that was injured from $70 \mathrm{~cm}$ responded with uniform and severe inflammation, whereas the groups 30,45 and $60 \mathrm{~cm}$ showed inflammation in some regions of the tissue with mild and moderate infiltrates.

Conclusion: The method with the 324-gram mass dropped from a 70-cm height onto the gastrocnemius muscle of rats seems to be the most suitable for the production of muscle injury in these animals after 72 hours, showing an important inflammatory infiltrate.

Key words: Inflammation. Muscle, Skeletal. Contusions. Rats. 


\section{Introduction}

Mechanical injuries are the most common type of skeletal muscle injuries, and are classified into one of the following areas: strain, laceration and contusion ${ }^{1}$. Muscular injuries have broad implications among professional athletes, standing out as approximately $30 \%$ of injuries sustained in sports that are mostly caused by mechanical trauma ${ }^{2}$. The lesions generated by shear loads are the most frequent and can result in contusion, sprains or lacerations. The variation occurs according to the mechanism of trauma, occurring most often in the lower limbs ${ }^{3,4}$.

Muscle injury accounts for approximately $90 \%$ of sports injuries, and occurs when a muscle is damaged by a significant compressive force generating high energy impact, which rapidly compresses local tissues, such as a direct knock. That is a common mechanism in contact sports ${ }^{1,5}$. In order to replicate the musculoskeletal injuries resulting from trauma, especially to then test the effect of a drug, some production models of animal lesion are proposed in the literature. However, the severity of the lesion generated by these devices can vary in each study due to the mechanism used to produce the trauma ${ }^{6}$.

The injury of production models seek to simulate the mechanism that occurs in practice, particularly in contact sports ${ }^{7}$. Some models using a falling mass onto the animal muscle have been reported in the literature, in which a density slides to directly contact the animal's muscle - usually being the gastrocnemius the most widely used muscle to these assessments ${ }^{8-12}$.

This technique replicates the original injury mechanism, often seen in clinical practice and that has also been used in studies to assess acute inflammatory lesion and trials testing drugs and treatments in this type of lesion ${ }^{13,14}$. However, there is still no consensus in the literature about the mechanism of injury, and different studies show a relative discrepancy about the fillers used and the heights mass drop onto the limbs. Thus, inflammatory responses developed in animals vary depending on the impact of the force generated in the muscles ${ }^{6}$.

The aim of this study was to develop a method for the production of acute muscular injury in rats with different height mass drop. It is expected that the results can be later employed to create a baseline in future studies in which therapeutic modalities of treatments for injured muscle may be compared.

\section{- Methods}

Experimental protocols and procedures were approved by the Ethics Committee of the Universidade Federal do Vale do São Francisco under the number 0006/110414.

Experiments were performed on twelve female adult Wistar rats (200.0 to $300.0 \mathrm{~g}$ ). The animals were randomly housed in appropriate cages at $22 \pm 2^{\circ} \mathrm{C}$ on a 12-hour light-dark cycle with free access to food and water. The animals were acclimatized for four days before beginning the experiments. Rats were allocated into four groups of three rats each, and in each group, the right gastrocnemius muscles were traumatized once and the left limber was used as control.

\section{Equipment for muscle contusion}

The $20 \times 12 \mathrm{~cm}$ base of the contusion device was made of iron. A $3 / 4$ PVC tube (135 $\mathrm{cm}$ of height and $8 \mathrm{~mm}$ of diameter) was used to drive the mass of $324 \mathrm{~g}$ that was used to contuse the leg of the animal (Figure 1). A 60$\mathrm{cm}$ fixed metal rod was used to support the tube. Four different heights $(30,45,60$ and $70 \mathrm{~cm}$ ) were made on the tube, and in each height a small opening was made to facilitate the sliding of the iron rod. 


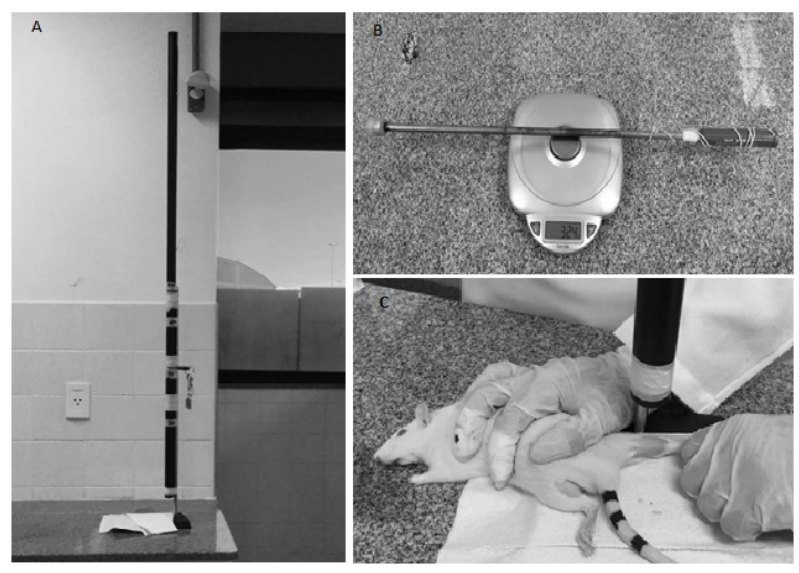

Figure 1 - Muscle contusion device. A, device with pre-set times to drop the mass. B, the 324gram cylindrical weight used to cause injury. C, positioning of the animal for the injury.

The iron rod inside the tube was fixed at a certain point attached by a key. Immediately after the withdrawal of the key, the rod slid until it reached the right hind limb. Thus, we could get four drops of the same mass, with varying kinetic energy of the drops. Therefore, the kinetic energies of $0.970 \mathrm{~J}, 1.455 \mathrm{~J}, 1.940$ $\mathrm{J}$ and $2.2634 \mathrm{~J}$ were obtained through the heights of $30,45,60$ and $70 \mathrm{~cm}$, respectively.

\section{Contusion model}

Before being injured, the animals were weighed and anaesthetized. The ketamine and xylazine $(80.0$ and $10.0 \mathrm{mg} / \mathrm{kg}$ body weight, respectively) were administrated through intraperitoneal (i.p.) anesthesia. The hind limbs were shaved and cleaned with alcohol; the measurement of its diameter was made with the aid of a digital caliper, and the circumference of the medial region of the muscle was evaluated through perimetry with the aid of tape (Cescorf ${ }^{\circledR}$ ). All measurements were performed prior to the injury and $72 \mathrm{~h}$ after injury, before euthanasia.

The mid-belly region of the gastrocnemius was determined through palpation and marked with a permanent marker. Each animal was positioned prone in the injury device with the hind limb fully extended on the leg holder and clamped into position. That ensured an impact directly over the mid-belly region of the gastrocnemius muscle. A metal mass fell through a guide tube causing the injury. The mass ( $324 \mathrm{~g}$ ) was dropped once from a height of $30,45,60$ or $70 \mathrm{~cm}$ depending on the group, in the midbelly region of the gastrocnemius muscles. Left gastrocnemius (LG) muscles were not injured and they were considered as control muscles.

\section{Histological analysis}

After $72 \mathrm{~h}$ of the injury, the rats were anaesthetized and sacrificed. The paw tissues were removed, fixed in $10 \%$ formalin in PBS, embedded in paraffin, and cut into 4- $\mu$ m-thick sections. The sections were stained by hematoxylin-eosin for histological analysis. A representative area was selected for qualitative light microscopic analysis of the inflammatory cellular response with a 10x objective. The inflammatory response was analyzed qualitatively according to the presence of inflammatory cells. Then, the lesion was classified as "mild", "moderate" and "severe". Histological analysis was performed by a specialist and based on the literature ${ }^{12}$.

\section{Statistical analysis}

Descriptive statistics was used to determine the mean and standard deviation of diameter and circumference of muscles before and after the injury. A 95\% confidence interval was used. SPSS for Windows, 15.0 version, was used for data analysis in this study.

\section{- Results}

\section{Macroscopic analysis of the gastrocnemius muscle after injury}

The macroscopic aspect of the gastrocnemius muscle showed a slight change in the color of the injured muscle 
of the animals only in groups of 60 and 70 $\mathrm{cm}$. The descriptive values of diameter and circumference measurements of the lower limbs measured before and 72 hours after injury and measurements between the injured and control limbs are show in Table 1.

Table 1 - Values of diameter and circumference measurements of the lower limbs of animals before and 72 hours after injury.

\begin{tabular}{|c|c|c|c|c|}
\hline \multirow[b]{2}{*}{ Group } & \multicolumn{2}{|l|}{ Diameter (mm) } & \multicolumn{2}{|l|}{ Circumference $(\mathrm{cm})$} \\
\hline & Before & After & Before & After \\
\hline $\mathrm{G} 1(35 \mathrm{~cm})$ & $\begin{array}{l}0.487 \pm 0.290 \\
(C l 95 \%: 0.413-0.560)\end{array}$ & $\begin{array}{l}0.403 \pm 0.008 \\
\text { (Cl 95\%: } 0.383-0.424)\end{array}$ & $\begin{array}{l}5.26 \pm 0.23 \\
(C l 95 \%: 4.69-5.84)\end{array}$ & $\begin{array}{l}4.93 \pm 0.29 \\
\text { (Cl 95\%: } 4.64-5.22)\end{array}$ \\
\hline $\mathrm{G} 2(40 \mathrm{~cm})$ & $\begin{array}{l}0.466 \pm 0.61 \\
(C l 95 \%: 0.314-0.617)\end{array}$ & $\begin{array}{l}0.433 \pm 0.013 \\
\text { (Cl 95\%: } 0.400-0.466)\end{array}$ & $\begin{array}{l}5.03 \pm 0.37 \\
(\mathrm{Cl} 95 \%: 4.09-5.97)\end{array}$ & $\begin{array}{l}4.56 \pm 0.05 \\
\text { (Cl 95\%: } 4.42-4.71)\end{array}$ \\
\hline $\mathrm{G} 3(60 \mathrm{~cm})$ & $\begin{array}{l}0.452 \pm 0.213 \\
\text { (Cl 95\%: } 0.398-0.505)\end{array}$ & $\begin{array}{l}0.446 \pm 0.006 \\
\text { (Cl 95\%: } 0.430-0.463)\end{array}$ & $\begin{array}{l}5.13 \pm 0.15 \\
(C l 95 \%: 4.75-5.51)\end{array}$ & $\begin{array}{l}5.16 \pm 0.35 \\
\text { (Cl 95\%: } 4.24-6.03)\end{array}$ \\
\hline $\mathrm{G} 4(70 \mathrm{~cm})$ & $\begin{array}{l}0.468 \pm 0.301 \\
(\mathrm{Cl} 95 \%: 0.393-0.543)\end{array}$ & $\begin{array}{l}0.441 \pm 0.017 \\
(\mathrm{Cl} 95 \%: 0.398-0.485)\end{array}$ & $\begin{array}{l}5.00 \pm 0.20 \\
(C I 95 \%: 4.50-5.49)\end{array}$ & $\begin{array}{l}5.03 \pm 0.25 \\
(\mathrm{Cl} 95 \%: 4.40-5.65)\end{array}$ \\
\hline
\end{tabular}

$\mathrm{Cl}$ : Confidence Interval

Microscopic analysis of the gastrocnemius muscle submitted to injury

The microscopic analysis of control muscles showed normal morphology and signs of inflammation were not observed. Figure 2 illustrates the aspect of the tissues $72 \mathrm{~h}$ after injury from the impact of a 324-gram mass from different heights $(30,45,60$ and $70 \mathrm{~cm})$.

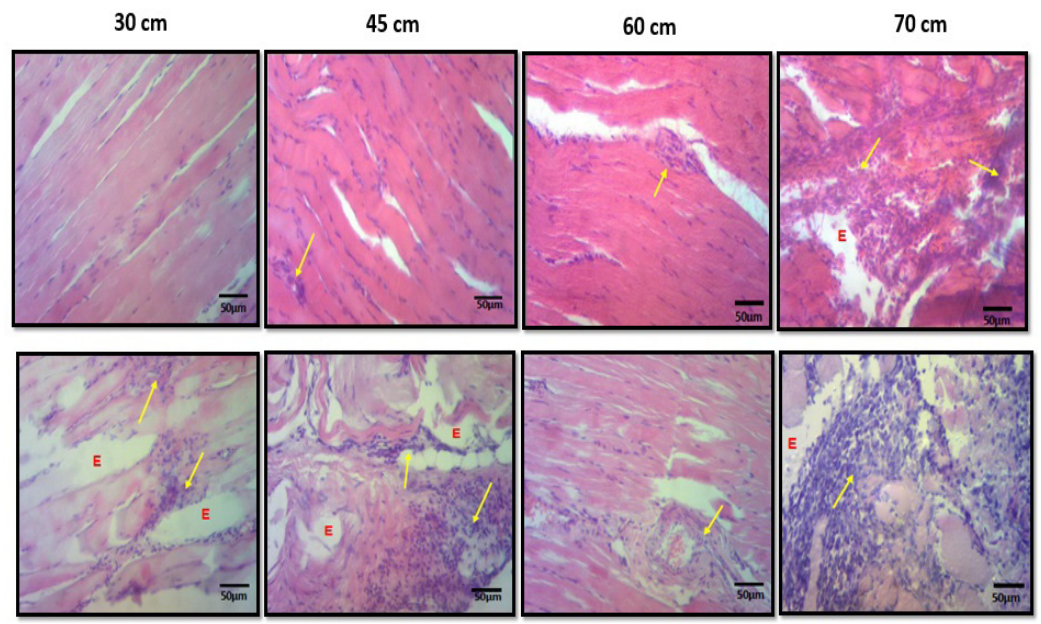

Figure 2 - H\&E Histological aspect of the injured gastrocnemius muscles of rat paws from different impacts. Regions of inflammatory infiltrate and degeneration of muscle fibers are indicated by arrows and the edema is indicated by letter $E$.

The impact of the 324-gram mass from $30-\mathrm{cm}$ height onto the right hind limb showed no uniformity in its histological analysis. In some regions, inflammatory signals were not identified, while other areas of the same tissue showed mild signs of inflammation with edema and mild inflammatory infiltrate with undifferentiated spindle cells.

Similarly, the animals in both the $45-\mathrm{cm}$ and $60-\mathrm{cm}$ groups also responded to the lesion in different ways, with the presence of nonuniform inflammatory infiltrate and regions of 
tissue without apparent injury, and others with moderate inflammatory signals like increased cellularity and interstitial inflammatory cells adhered to the muscular fibers.

The histological aspect of the injured muscle of rats that received a contusion from a $70-\mathrm{cm}$ height was different from the others. The inflammatory response had uniform appearance with inflammatory infiltrate signals in all regions of the tissue. There was the presence of fibroblasts between mononuclear and polymorphonuclear cells, and more intense lesions with inflammatory cells in almost all regions of the muscle could be observed, as well as edema and necrosis of the muscle fibers.

\section{Discussion}

Many models have been used to replicate skeletal muscle injury associated with trauma in animal models to evaluate the effect of pharmacological tests as physiotherapeutic procedures, such as cryotherapy, massage, phonophoresis and others ${ }^{12,15,16}$. However, these studies have a discrepancy regarding the method, device, impact and level of severity ${ }^{6}$. The purpose of our study was to develop a new contusion device that would allow different degrees of injury to be generated in rats and determine the best protocol to be applied with security by histological analysis of muscle tissue.

The histological analysis of the musculoskeletal tissue of the animals of each group demonstrated that the greater the height of the mass, the stronger was the muscle inflammatory response. When the drop height was increased to 30,45 and $60 \mathrm{~cm}$ the injury was mild to moderate, with regions where no inflammatory cells were identified. The $70-\mathrm{cm}$ height is likely to have showed another level of severity (moderate to severe). On the other hand, unlike McBrier et al. ${ }^{7}$, there was no bone fracture cases of the tibia or fibula.

McBrier et $a{ }^{7}$, in their study, also assessed changes in muscle response to injury caused by different heights, though injury severity was determined using magnetic resonance imaging. When a 267-gram weight was dropped from a height between 40 and $50 \mathrm{~cm}$, it produced one level of injury (mild to moderate), and when the drop height was increased to $60 \mathrm{~cm}$ or higher, another level of severity (moderate to severe) was sustained. The $70-\mathrm{cm}$ height or greater resulted in fractures of the tibia and fibula. In our study, we used similar heights and more weight, but there was no fracture.

Although an analysis with magnetic resonance imaging is valid for the injury classification, the majority of studies uses similar methods to prove the efficacy of drugs with anti-inflammatory potential. The histological analysis is more used in the qualitative or quantitative comparisons of tissue to compare the results of the methods tested ${ }^{12,15,17}$.

Abreu et al. ${ }^{12}$ caused a muscle injury and demonstrated the anti-inflammatory effect of the Lychnophora pinaster gel after acute injury in the gastrocnemius muscle of rats. The injury was caused by a 30-cm-high drop of a 300-gram mass onto the lower limbs of rats. In this study, the similar methodology application showed a tissue with little infiltration areas and other regions without signs of inflammation. Minamoto et al. $^{18}$ analyzed the soleus muscle of rats after light bruising and recurring using a mass of $204 \mathrm{~g}$ loose to $16 \mathrm{~cm}$ in the posterior region of the lower limbs of 32 rats, and through histological analysis, abundant signs were found of acute damage-injured muscle, and major changes in tissue morphology. In another study, Minamoto and Salvini ${ }^{19}$ compared the morphology of the injury in the tibialis anterior generated by a single and periodic impact. However, the same researchers chose another method, they used other variables in the production of the injury, with a loose weight of $200 \mathrm{~g}$ at $36 \mathrm{~cm}$.

In order to verify the effects of the therapeutic ultrasound on the mechanical 
properties of the rat muscle after injury, another study induced mechanical trauma by a 200-gram weight at a $30-\mathrm{cm}$ height. However, the authors did not analyze the histological tissue response $\mathrm{e}^{20}$. This discrepancy between the methods employed for the production of injury in rats bore variations of height and kinetic energy used from those found in the literature ${ }^{7}$. Other studies also seek the development and validation of methods for producing muscle injury in rabbits ${ }^{21}$.

The method of choice in studies that use the injury model in animals should be safe when the new substance or treatment is tested. In studies whereby this injury is caused even using the same animal model, with the same characteristics, age and lack of training, the tissue response presents a variable way. Although all studies use models of control, the award of the effect of any type of treatment may be linked to the non-response of the tissue, rather than the effect of the treatment tested.

The mechanical trauma induced on the musculature in order to produce muscle injury in rats is applied in several studies where these methods are used to test anti-inflammatory treatments. However, even the muscle where the impact caused the damage by 30,45 and $60 \mathrm{~cm}$ regions without consistent signs of inflammatory response were identified. Thus, studies that analyze the action of drugs in the inflammatory process caused by mechanical trauma must choose more carefully methods of choice, and offer a way to study treatment interventions and determine their efficacy based on injury severity.

Our study had a limitation as we did not evaluate the contusion in other times plus $72 \mathrm{~h}$, and the response of the cells on tissue injury can be different in other hours after injury. Therefore, we suggest that the method of the drop height be increased to $70 \mathrm{~cm}$ and that it be the first choice for studies that evaluate the effect of anti-inflammatory treatments because this protocol presented a uniform lesion with intense inflammatory infiltrate. Further studies need to be done to confirm these findings and to study the mechanisms of action.

\section{Conclusion}

All protocols adopted stimulated muscle inflammatory response. The method with the 324-g mass dropped from the $70-\mathrm{cm}$ height onto the gastrocnemius muscle of rats seems to be the most suitable for the production of muscle injury in these animals for 72 hours, showing an important inflammatory infiltrate.

\section{References}

1. Järvinen $T A$, Järvinen $T L$, Kääriäinen $M$, Aärimaa V, Vaittinen S, Kalimo H, Järvinen $M$. Muscle injuries: optimising recovery. Best Pract Res Clin Rheumatol. 2007;21(2):31731. PMID: 17512485.

2. Ekstrand J, Hägglund $M$, Waldén $M$. Epidemiology of muscle injuries in professional football (soccer). Am J Sports Med. 2011;39(6):1226-32. PMID: 21335353.

3. Astur DC, Novaretti JV, Uehbe RK, Arliani GG, Moraes ER, de Castro Pochini A, Ejnisman B, Cohen M. Muscle injury: current perspectives and trends in Brazil. Rev Bras Ortop. 2014;49(6):573-80. PMID: 26229864.

4. Bratland-Sanda $S$, Sundgot-Borgen J, Myklebust G. Injuries and musculoskeletal pain among Norwegian group fitness instructors. Eur J Sport Sci. 2015;15(8):78492. PMID: 26255720.

5. Khattak MJ, Ahmad T, Rehman R, Umer M, Hasan SH, Ahmed M. Muscle healing and nerve regeneration in a muscle contusion model in the rat. J Bone Joint Surg $\mathrm{Br}$. 2010;92(6):894-9. PMID: 20513892.

6. Souza J, Gottfried C. Muscle injury: review of experimental models. J Electromyogr Kinesiol. 2013;23(6):1253-60. PMID: 24011855.

7. McBrier NM, Neuberger T, Okita N, Webb A, Sharkey N. Reliability and validity of a novel muscle contusion device. J Athl Train. 2009;44(3):275-8. PMID: 19478842.

8. Crisco JJ, Jokl P, Heinen GT, Connell MD, Panjabi MM. A muscle contusion injury model. Biomechanics, physiology, and 
histology. Am J Sports Med. 1994;22(5):70210. PMID: 7810797.

9. Crisco JJ, Hentel KD, Jackson WO, Goehner K, Jokl P. Maximal contraction lessens impact response in a muscle contusion model. J Biomech. 1996;29(10):1291-6. PMID: 8884474.

10.Ambrosio F, Ferrari RJ, Distefano G, Plassmeyer JM, Carvell GE, Deasy BM, Boninger ML, Fitzgerald GK, Huard J. Synergistic effect of treadmill running on stem-cell transplantation to heal injured skeletal muscle. Tissue Eng Part A. 2010;16(3):839-49. PMID: 19788347.

11.Puntel GO, Carvalho NR, Amaral GP, Lobato LD, Silveira SO, Daubermann MF, Barbosa NV, Rocha JB, Soares FA. Therapeutic cold: an effective kind to modulate the oxidative damage resulting of a skeletal muscle contusion. Free Radic Res. 2011;45(2):12538. PMID: 20942569.

12. Abreu VGC, Correa GM, Silva TM, Fontoura HS, Cara DC, Piló-Veloso D, Alcântara AF. Anti-inflammatory effects in muscle injury by transdermal application of gel with Lychnophora pinaster aerial parts using phonophoresis in rats. BMC Complement Altern Med. 2013;13(270):1-8. PMID: 24138803.

13.Silveira PC, Victor EG, Schefer D, Silva LA, Streck EL, Paula MM, Pinho RA. Effects of therapeutic pulsed ultrasound and dimethylsulfoxide (DMSO) phonophoresis on parameters of oxidative stress in traumatized muscle. Ultrasound Med Biol. 2010;36(1):44-50. PMID: 19900747.

14.Shu B, Yang Z, Li X, Zhang LQ. Effect of different intensity pulsed ultrasound on the restoration of rat skeletal muscle contusion. Cell Biochem Biophys. 2012;62(2):329-36. PMID: 22068832.

15.Deane M, Gregory M, Mars, M. The effect of a contusion injury on rabbit skeletal muscle: a morphological study. OAJoST. 2013;1:1-8. doi: 10.11131/2013/100012.

16.Garg K, Corona BT, Walters TJ.Therapeutic strategies for preventing skeletal muscle fibrosis after injury. Front Pharmacol. 2015;6(87):1-9. PMID: 25954202.

17. Facio FA, Minamoto VB. Morphological analyze in a short and long-term of tibialis anterior muscle after contusion. Fisioter Mov. 2006;19 (1):73-80.

18. Minamoto VB, Grazziano CR, Salvini TF. Effect of single and periodic contusion on the rat soleus muscle at different stages of regeneration. Anat Rec. 1999;254(2):281-7. PMID: 9972813.

19.Minamoto VB, Salvini TF. Long-term regeneration of rat skeletal muscle after periodic contusions. Rev Bras Fisioter. 2002;6(3):147-54. PMID: 11668355.

20. Matheus JPC, Oliveira FB, Gomide LB, Milani JGPO, Volpon JB, Shimano AC. Effects of therapeutic ultrasound on the mechanical properties of skeletal muscles after contusion. Rev Bras Fisioter. 2008;12(3):241-7. doi: 10.1590/S141335552008000300013.

21.Deane MN, Gregory M, Mars M, Bester L. Creation of a contusion injury in rabbit skeletal muscle using a drop-mass technique. J S Afr Vet Assoc. 2013;84(1):1-6. doi: 10.4102/jsava.v84i1.957.

\section{Correspondence:}

Jackson Roberto Guedes da Silva Almeida

Avenida José de Sá Maniçoba, s/n

Caixa-postal: 252

56304205 Petrolina - PE Brasil

Tel.: (55 87)2101-6862

jackson.guedes@univasf.edu.br

Received: Jan 16, 2017

Review: Mar 15, 2017

Accepted: Apr 18, 2017
Conflict of interest: none

Financial source: none 